\title{
Development and Optimisation of Mucoadhesive Films for Enhanced Drug Delivery in Treatment of Lichen Planus
}

\author{
Manima Maharjan, ${ }^{1}$ Beny Baby, ${ }^{2}$ Sabina Sankhi, ${ }^{3}$ B.V.S Anusha, ${ }^{4}$ Sujit Shrestha,,${ }^{5}$ Nirmal Raj Marasine ${ }^{6}$ \\ 1,2,4,5 Department of Pharmaceutics, Faculty of Pharmacy, Rajiv Gandhi University of Health Sciences, Bangalore, Karnataka, India; \\ ${ }^{3}$ Department of Pharmacy, Modern Technical College, Sanepa, Lalitpur, Nepal; \\ ${ }^{6}$ Department of Pharmacy, Karnali College of Health Science, Gaushala, Kathmandu, Nepal.
}

Correspondence:

Nirmal Raj Marasine. Email: nirmalmarasine@gmail.com

\begin{abstract}
Introduction: Mucoadhesive buccal films are most recently developed and preferred over buccal tablet because of the flexibility, better bioavailability, cost effectiveness, and good patient compliance it offers
\end{abstract}

Objective: The study aimed to formulate mucoadhesive films of Clobetasol Propionate with reduced side effects, controlled release and better patient compliance, suitable for the management of oral lichen planus.

Methods: Clobetasol Propionate Buccal Films were prepared by the incorporation of the Clobetasol Propionate along with polymers like Hydroxy Propyl Methyl Cellulose (HPMC) K4M, polyethylene glycol 400 and glycerol by solvent casting method.

Results: The drug content of all the formulations was found to be $85.04 \%$ to $93.14 \%$. The swelling index of all formulations of Clobetasol Propionate mucoadhesive buccal film was found to be $82 \%$ to 94.07\%. Formulation F14 which contains Hydroxy Propyl Methyl Cellulose K4M (1\%), and polyethylene glycol 400 (1\%) exhibited better results compared to other combination of polymers in different concentration. It showed swelling index of $94.07 \%$. Drug content was found to be $91 \%$ and showed release of drug up to $95.05 \%$ in 12 hours. The optimised formula showed no significant changes on stability studies when stored at $40^{\circ} \mathrm{C} / 75 \% \mathrm{RH}$ for three months.

Conclusions: The application of mucoadhesive buccal film containing Clobetasol Propionate appeared to be effective, avoiding the side effects and the data obtained in the study suggested that buccal films can be successfully designed to give controlled drug delivery.

Keywords: Buccal films; clobetasol propionate; hydroxy propyl methyl cellulose; mucoadhesive; polyethylene glycol; solvent casting method.

\section{INTRODUCTION}

Mucoadhesive buccal films are most recently developed and preferred over buccal tablet because it offers flexibility, better bioavailability, cost effectiveness, and good patient compliance. ${ }^{1,2}$ Films employs a water dissolving polymer that allows the dosage form to quickly hydrate, adhere and dissolve when placed on the tongue or in the oral cavity resulting in systemic drug delivery. ${ }^{1}$ Oral lichen planus (OLP), a

Citation: Maharjan M, Baby B, Sankhi S, Anusha B.V.S, Shrestha $\mathrm{S}$, Marasine NR. Development and optimisation of mucoadhesive films for enhanced drug delivery in treatment of lichen planus. Nepal J Health Sci. 2021 Jan-Jun;1(1): 29-36 
chronic autoimmune mucocutaneous inflammatory disease, affects the mucosal lining of the oral cavity causing white striations, papules or plaque with or without erythema and ulceration. ${ }^{3}$ It affects $1-3 \%$ of the world's population by triggering cytotoxic CD8+ T-cells causing apoptosis of the basal cells of the oral epithelium. ${ }^{3,4}$

Clobetasol propionate demonstrate anti-inflammatory, vasoconstrictive, anti-proliferative, and immunosuppressive activities, which are responsible for excellent recovery and reduced relapses of lichen planus, psoriasis, and atopic dermatitis. ${ }^{5}$ However, its buccal dosage form are not commercially available and semisolid preparation poses difficulties in applying the medication at various oral sites, taste alterations, limited contact time, and possibility of swallowing of a formulation. ${ }^{4}$ Hence, this study aimed to formulate its mucoadhesive films with reduced side effects, controlled release and better patient compliance, suitable for the management of oral lichen planus.

\section{MeTHODS}

Clobetasol Propionate, Hydroxy Propyl Methyl Cellulose K4M, Polyethylene glycol (PEG 400) and
Glycerol were procured from yarrow chemicals, Pvt. Ltd, Mumbai, India.

Mucoadhesive buccal films of Clobetasol propionate were prepared by solvent casting technique using film forming mucoadhesive polymers. HPMC was weighed accurately and dissolved in methanol. The beaker containing polymer and methanol was kept aside for five minutes for swelling of the polymer. Then, the solution was stirred continuously until it got dissolved. Then propylene glycol (PEG 400) was added to the polymer solution and kept aside. Simultaneously Clobetasol propionate was weighed accurately and dissolved in methanol in another beaker, stirred continuously until it got dissolved and kept aside. Both solutions were mixed together, stirred well, and kept aside for removal of all the air bubble. The mixed solution was then poured on to the mercury surface. After drying overnight, the dried film was covered with aluminum foil and stored in desiccators until further use. The compositions of different formulation of Clobetasol Propionate mucoadhesive buccal films are shown in Table 1 and 2., ${ }^{2,6}$

Table 1: Factors and levels used for optimisation of Clobestasol-17 Propionate mucoadhesive buccal film.

\begin{tabular}{|l|c|c|c|}
\multicolumn{1}{c|}{ Variable factors } & \multicolumn{2}{|c|}{ Level } & Optimised level (F14) \\
\cline { 2 - 4 } & $\mathbf{- 1}$ & $\mathbf{1}$ & 0.966 \\
\hline HPMC K4M (\%) & 0.5 & 1 & 1 \\
\hline PEG (\%) & 0.5 & 1 & \\
\hline
\end{tabular}

Table 2: Compositions of various formulations of Clobetasol-17 Propionate mucoadhesive buccal film.

\begin{tabular}{|l|c|c|c|c|c|}
\hline Formulation Code & $\begin{array}{c}\text { Drug Code } \\
\text { (mg) }\end{array}$ & $\begin{array}{c}\text { HPMC K4M } \\
(\mathbf{\%})\end{array}$ & PEG 400(\%) & $\begin{array}{c}\text { Glycerol } \\
\text { (mL) }\end{array}$ & $\begin{array}{c}\text { Solvent } \\
\text { (mL) }\end{array}$ \\
\hline F1 & 0.7 & 0.75 & 1 & 0.45 & 2 \\
\hline F2 & 0.7 & 0.5 & 0.5 & 0.45 & 2 \\
\hline F3 & 0.7 & 0.5 & 0.75 & 0.45 & 2 \\
\hline F4 & 0.7 & 0.75 & 0.75 & 0.45 & 2 \\
\hline F5 & 0.7 & 0.75 & 0.75 & 0.45 & 2 \\
\hline F6 & 0.7 & 1 & 1 & 0.45 & 2 \\
\hline F7 & 0.7 & 1 & 0.5 & 0.45 & 2 \\
\hline F8 & 0.7 & 1 & 0.5 & 0.45 & 2 \\
\hline F9 & 0.7 & 1 & 0.75 & 0.45 & 2 \\
\hline F10 & 0.7 & 0.5 & 0.5 & 0.45 & 2 \\
\hline F11 & 0.7 & 0.75 & 0.5 & 0.45 & 2 \\
\hline F12 & 0.7 & 0.5 & 1 & 0.45 & 2 \\
\hline F13 & 0.7 & 0.5 & 1 & 0.45 & 2 \\
\hline
\end{tabular}

Evaluation of Clobetasol-17 Propionate mucoadhesive buccal film 
Film thickness: The thickness of films was measured at three different places using a screw gauge. The film was inserted into the screw gauge making sure that the pointer was at zero. The reading was noted down in triplicate form and the average thickness of the film was determined..$^{2,7}$

Folding endurance: Folding endurance was determined by repeatedly folding a small strip of film at a same place till it broke. The number of the times the patch could be folded at the same place without breaking gives the value of folding endurance which indicates the brittleness of the film. Folding endurance was determined in triplicate and the mean value was calculated. ${ }^{2,8}$

Drug content: The amount of Clobetasol Propionate in the mucoadhesive buccal film were estimated by cutting the film in $2 \times 2 \mathrm{~cm}^{2}$ in a $100 \mathrm{~mL}$ volumetric flask containing $100 \mathrm{~mL}$ of $\mathrm{pH} 6.8$ phosphate buffer solution. The contents were kept aside for 24 hours to completely dissolve the patch. The sample were then suitably diluted if necessary with $\mathrm{pH} 6.8$ phosphate buffer and analysed for Clobetasol Propionate content by UV spectrophotometrically (UV 1700 SHIMADZU) at $239 \mathrm{~nm} .7,9$

Swelling studies: Buccal film were individually weighed (W1) and were placed separately in 2\% agar gel plates with the core facing the gel surface and was incubated at $37^{\circ} \mathrm{C} \pm 1^{\circ} \mathrm{C}$. After definite time interval of five minutes until one hour the film were removed from the petridish and excess surface water was removed carefully with the filter paper. The swollen films were then reweighed (W2) and the swelling index was calculated using following formula: ${ }^{10}$

\section{Swelling index $=\left(\mathrm{W}_{2}-\mathrm{W} 1\right)$

$$
\text { W1 }
$$

Where, W1 is the initial weight of film and W2 is the final weight of film

In vitro drug diffusion studies: In vitro drug release study was performed using Franz diffusion cell with a receptor compartment capacity of $150 \mathrm{~mL}$. The dialysis membrane was mounted between the donor and the receptor compartment of the diffusion cell. The film was placed on the dialysis membrane and was covered with aluminum foil. The receptor compartment of the diffusion cell was filled with $\mathrm{pH} 6.8$ phosphate buffer. The whole set up was fixed on a hot plate magnetic stirrer and solution in the receptor compartment was constantly and continuously stirred using magnetic beads and the temperature was maintained at $37^{\circ}$ $\mathrm{C} \pm 1^{\circ} \mathrm{C}$. The samples were withdrawn at different time intervals $(1,2,3,4,5,6,7,8,9,10,11$ and 12 hours) and every time replaced with equal volume of fresh dissolution medium. The samples were analysed for drug content spectrophotometrically at $239 \mathrm{~nm} .{ }^{11}$

Kinetic release study: To study the mechanism of the drug release rate kinetics of the formulation, the obtained data were fitted into \% Cumulative Drug Release (CDR) vs. time for Zero order kinetics, Log \% CDR remaining vs. time for First order kinetics, \% CDR vs square root time for Higuchi model and Log \% CDR vs Log t for Koresmeyer's model were plotted to get $\mathrm{R}^{2}$ values.

Experimental design and Optimisation: According to the results obtained from the previous studies, the independent variables such as HPMC K4M concentration and the PEG concentration would significantly affects the swelling index, drug content and drug release profile of mucoadhesive films. The Central Composite design using Design- Expert software (version 11.1.2.0, Stat-Ease) was conducted to Figure out the effect of these variables on the properties of mucoadhesive buccal films in a fewer experimental runs. The effect of two variables including HPMC K4M concentration from $0.5 \%$ to $1 \%$ and the PEG concentration from $0.5 \%$ to $1 \%$ on mucoadhesive films properties such as swelling index (\%), drug content (\%) and Clobetasol-17 Propionate release in 24 hours was investigated in nine runs. Quantitative variables were studied at two experimental levels -1 and +1 . ANOVA was used for evaluation of the significance of independent variables on responses.

Accelerated stability studies: The purpose of accelerated stability testing is to provide evidence on how the quality of a drug product varies with time under the influence of a variety of environment factors such as temperature, humidity and light and to establish a re-test period for the drug substance or a shelf life for the drug product and recommended storage conditions. To assess the drug and formulation stability, 
stability studies were done according to ICH guidelines Q1C. Stability studies were carried out on the films of most satisfactory as per ICH guidelines Q1C. The optimised formulation was stored in sealed aluminium foil. These were stored at room temperature for three months and tested for period of one month interval. Films were evaluated for in vitro drug release and various physical characteristics. ${ }^{7}$

\section{RESULTS}

Table 3: Film thickness, folding endurance, and drug content of all the formulations $(\mathrm{N}=3)$.

\begin{tabular}{|c|c|c|c|}
\hline Formulation Code & Film thickness (mm) & Folding endurance & Drug content (\%) \\
\hline $\mathrm{F} 1$ & $0.25 \pm 0.02$ & 86 & $92 \pm 0.10$ \\
\hline F2 & $0.29 \pm 0.05$ & 89 & $82.04 \pm 0.05$ \\
\hline $\mathrm{F}_{3}$ & $0.24 \pm 0.09$ & 84 & $86.02 \pm 0.09$ \\
\hline $\mathrm{F} 4$ & $0.31 \pm 0.09$ & 92 & $90.04 \pm 0.02$ \\
\hline $\mathrm{F}_{5}$ & $0.21 \pm 0.04$ & 94 & $89.06 \pm 0.08$ \\
\hline F6 & $0.24 \pm 0.03$ & 90 & $93 \pm 0.02$ \\
\hline F7 & $0.31 \pm 0.08$ & 84 & $87.02 \pm 0.13$ \\
\hline F8 & $0.26 \pm 0.06$ & 96 & $88 \pm 0.10$ \\
\hline F9 & $0.22 \pm 0.04$ & 94 & $91.02 \pm 0.09$ \\
\hline F10 & $0.24 \pm 0.09$ & 93 & $87.04 \pm 0.14$ \\
\hline F11 & $0.20 \pm 0.10$ & 94 & $93.09 \pm 0.05$ \\
\hline F12 & $0.26 \pm 0.07$ & 90 & $85 \pm 0.10$ \\
\hline $\mathrm{F} 13$ & $0.23 \pm 0.08$ & 89 & $86 \pm 0.09$ \\
\hline F14 & $0.29 \pm 0.05$ & 86 & $89.06 \pm 0.08$ \\
\hline
\end{tabular}

\section{Swelling index}

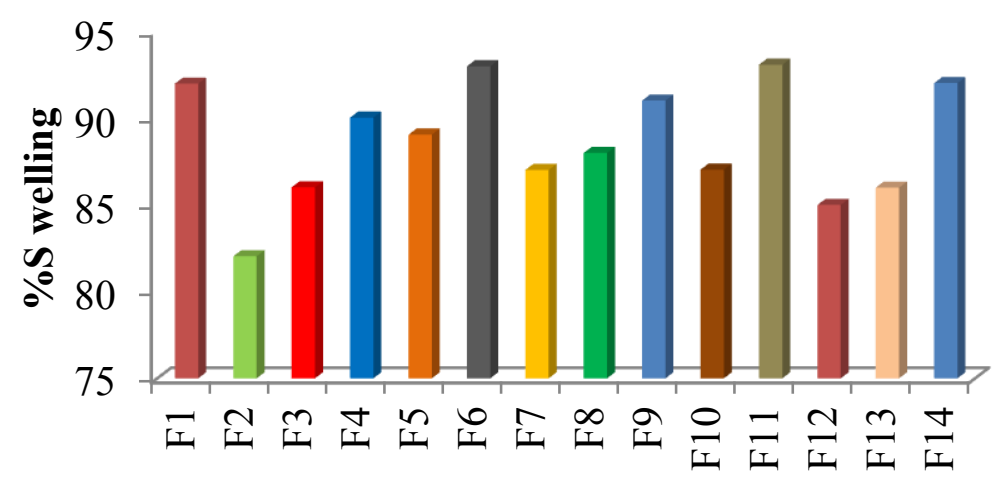

Formulation Code

Figure 1: Swelling index of formulation F1 to F1o (data are represented as $\operatorname{Mean} \pm \mathrm{SD}, \mathrm{N}=3$ ). 


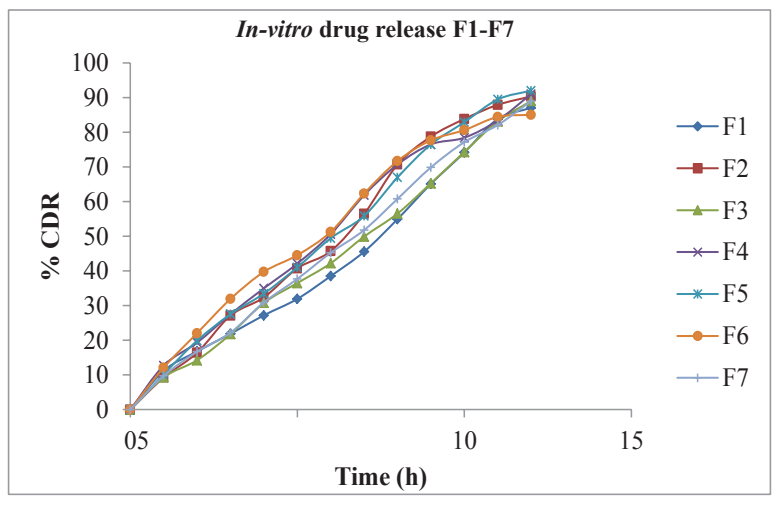

Figure 2: In-vitro drug release profile of prepared formulations $\mathrm{F}_{1}-\mathrm{F}_{7}$ (data are represented as Mean $\pm \mathrm{SD}, \mathrm{N}=3$ ).

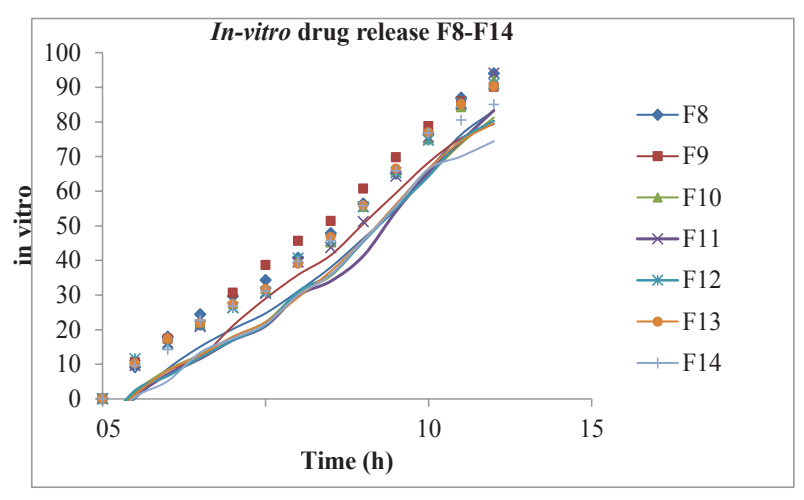

Figure 3: In-vitro drug release profile of prepared formulations F8-F14 (data are represented as Mean $\pm \mathrm{SD}, \mathrm{N}=3$ ).

Table 4: Curve fitting for all the formulations.

\begin{tabular}{|l|c|c|c|c|c|}
\hline $\begin{array}{c}\text { Formulation } \\
\text { code }\end{array}$ & Zero order & First order & Higuchi model & $\begin{array}{c}\text { Koresmeyer } \\
\text { peppas }\end{array}$ & n-value \\
\hline F1 & 0.9867 & 0.8635 & 0.9261 & 0.9782 & 0.9765 \\
\hline F2 & 0.9912 & 0.9317 & 0.9712 & 0.9912 & 0.9805 \\
\hline F3 & 0.9975 & 0.9013 & 0.9623 & 0.9977 & 0.9912 \\
\hline F4 & 0.9978 & 0.9493 & 0.981 & 0.994 & 0.8841 \\
\hline F5 & 0.9952 & 0.9271 & 0.975 & 0.9943 & 0.8968 \\
\hline F7 & 0.9795 & 0.9776 & 0.9883 & 0.9921 & 0.7886 \\
\hline F8 & 0.9984 & 0.9302 & 0.9715 & 0.9971 & 09659 \\
\hline F9 & 0.9897 & 0.8232 & 0.9369 & 0.9848 & 0.9838 \\
\hline F11 & 0.9971 & 0.9145 & 0.9627 & 0.9943 & 0.9881 \\
\hline F12 & 0.9859 & 0.8434 & 0.9229 & 0.9779 & 0.9766 \\
\hline F13 & 0.9852 & 0.8076 & 0.9242 & 0.9739 & 0.9807 \\
\hline F14 & 0.9847 & 0.8534 & 0.9215 & 0.9735 & 0.9697 \\
\hline
\end{tabular}

Table 5: Summary of analysis of variance for models and independent variables.

\begin{tabular}{|c|c|c|c|c|c|c|c|c|}
\hline \multirow{2}{*}{ Response } & \multirow{2}{*}{ Model } & \multirow{2}{*}{ Model intercept } & \multicolumn{6}{|c|}{ p-value } \\
\hline & & & Model & $\mathbf{A}$ & B & $\mathbf{A B}$ & A2 & B2 \\
\hline $\begin{array}{l}\text { Swelling } \\
\text { index (R1) }\end{array}$ & Quadratic & 90.75 & 0.0335 & 0.0091 & 0.1525 & 0.2217 & 0.347 & 0.6687 \\
\hline $\begin{array}{l}\text { Drug content } \\
\text { (R2) }\end{array}$ & Quadratic & 89.98 & 0.0281 & 0.3228 & 0.0279 & 0.0615 & - & - \\
\hline $\begin{array}{l}\text { Drug release } \\
24 \mathrm{~h}\left(\mathrm{R}_{3}\right)\end{array}$ & Quadratic & 90.05 & 0.0400 & 0.2005 & 0.0114 & 0.0863 & - & - \\
\hline
\end{tabular}




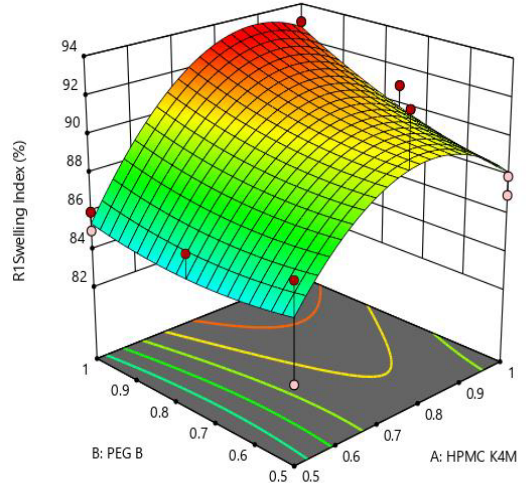

Figure 4: 3D graph of swelling index.

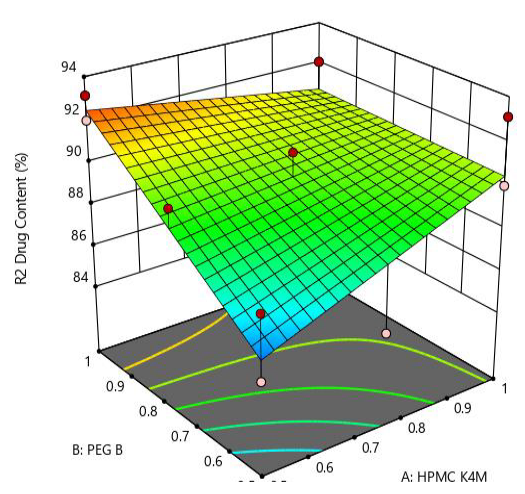

Figure 5: 3D graph of drug content.

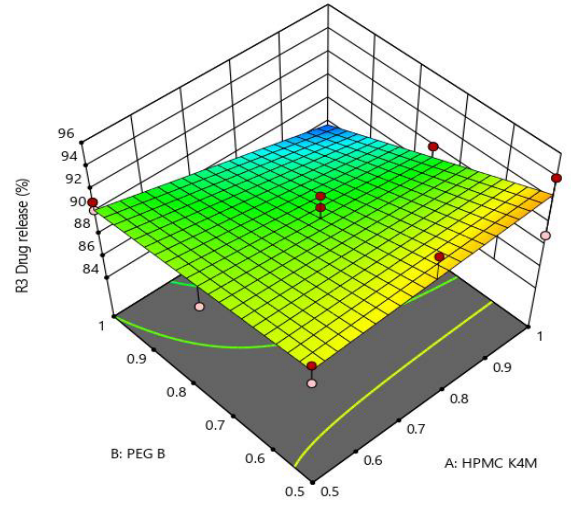

Figure 6: 3D graph of drug

Table 6: Accelerated stability studies

\begin{tabular}{|l|c|c|c|}
\hline \multicolumn{1}{|c|}{ Time } & Swelling index (\%) & Drug content (\%) & Drug release (\%) \\
\hline Initial & 92.03 & 89.06 & 85.02 \\
\hline 1st month & 91.17 & 86.12 & 84.89 \\
\hline 2nd month & 89.79 & 84.38 & 83.99 \\
\hline 3rd month & 86.32 & 82.76 & 82.92 \\
\hline
\end{tabular}

\section{DISCUSSIONS}

Film thickness: The thickness of the developed formulations $\mathrm{F} 1$ to $\mathrm{F} 13$ varied from 0.20 to $0.31 \mathrm{~mm}$ which was found to be uniform. The thickness of the optimised formula F14 was found to be $0.29 \mathrm{~mm}$. The thickness of the mucoadhesive film increases with increase in HPMC K4M concentration. The standard deviation values were less than 1 for all formulations indicating uniformity of the films (Table 3).

Folding endurance: Folding endurance of the mucoadhesive films from $\mathrm{F} 1$ to $\mathrm{F} 13$ varied from $84-89$ and for the optimised formulation F14 it was found to be 86 shown in Table 3. Folding endurance of the film increases with the increase in the concentration of HPMC K4M proportion.

Drug content: The results obtained for the drug content of the Clobetasol-17 propionate mucoadhesive film were shown in Table 3. Good uniformity of Clobetasol-17 Propionate was observed in all buccal film. The drug content was found to be within the range of $85.04 \%$ to $93.14 \%$. The drug content of the optimised formulation F14 was found to be $89.06 \%$.
It may be due to less concentration of polymer. It was clear that there was uniform distribution of Clobetasol-17 Propionate in all the formulations.

Swelling index: The results of the swelling index of the formulation $\mathrm{F} 1$ to $\mathrm{F} 13$ (Figure 1) varied from $82.04 \%$ to $93.09 \%$ and the optimised formulation $\mathrm{F} 13$ was revealed to be $92.03 \%$. The water content remained in F13 was found to be more which showed high percentage of swelling index. The formulation F2 showed less percentage of swelling index.

In vitro drug diffusion studies: In vitro drug diffusion release of Clobetasol Propionate from the prepared mucoadhesive buccal films was studied in $\mathrm{pH} 6.8$ phosphate buffer for $12 \mathrm{~h}$. As the ratio of polymer increased the drug release decreased proportionally. The release rate from prepared formulation containing low polymer concentration was remarkably faster. This may be due to the combinations of other factors such as PEG 400, glycerol etc. In vitro drug release of all formulations was represented in Figure 2, 3. When the drug to polymer ratio increases the diffusion of dissolution medium into the buccal films was retarded 
which decreases the dissolving of active drug molecules which act as a rate controlling for the release of drug molecules.

Kinetic release study: To understand the release profile of the Clobetasol Propionate the drug release data obtained were fitted into different models. It suggests that the release of drug from the formulations may follow any one of these models. The $\mathrm{r}^{2}$ values of zero order of all the formulations have shown a higher value which indicates that the drug release is independent of the concentration of the dissolved substances. To understand the diffusion mechanism the data was fitted into Koresmeyer's Peppas equation, as the value of ' $n$ ' indicate between $0.5^{-1}$ the mechanism of drug release was understand to be non- fickian (Table 4).

Experimental Design and Optimisation: The results of the ANOVA demonstrate that the model was significant for all dependent variables (Table 5, Figure 3-5). Regression analysis was performed to understand the regression coefficients. All the independent variables or factors were found to be significant for all $\mathrm{R} 1, \mathrm{R} 2$ and $\mathrm{R} 3$ response variables. Quadratic model was found to be significant for all responses. From the results it is understand that all two factors plays an important role in the development of mucoadhesive buccal film.

Accelerated stability studies: These studies revealed that formulation F14 was stable in drug contents, no change in the physical appearance of the formulation and in vitro release after storage for two months at $40 \pm 2^{\circ} \mathrm{C}$ and $75 \pm 5 \%$ relative humidity (Table 6). The drug content of the formulation $\mathrm{F} 15$ stored at $40 \pm 2^{\circ} \mathrm{C}$ and $75 \pm 5 \%$ relative humidity was $84.89 \%, 83.99 \%$ and $82.92 \%$ respectively for 1 st, 2 nd, and 3 rd month. The swelling index was found to be $91.17 \%, 89.78 \%$ and $86.32 \% \%$ respectively for 1 st, 2 nd, and 3 rd month. It indicates that the Clobetasol-17 Propionate was stable in $40 \pm 2^{\circ} \mathrm{C}$ and $75 \pm 5 \%$ relative humidity.

\section{Conclusions}

From this study it is concluded that the Clobetasol-17 Propionate can be formulation in mucoadhesive buccal films. With the best possible polymers like HPMC K4M and PEG4Oo the drug can be formulated in the form of controlled manner buccal film which gives drug release up to 12 hours. The swelling index, drug content and drug release can be attained in desired level by altering the concentration of the polymer. It was concluded that the film properties and the drug release are affected by different factors. Formulation F14 containing HPMC K4M 0.996\%, PEG 400 1\% and Glycerol $0.45 \mathrm{~mL}$ showed better physicochemical properties and Clobetasol Propionate release rate compared to other formulations and was optimised as the best formulation. Hence, finally it was concluded that the prepared mucoadhesive buccal films of Clobetasol-17 Propionate may prove to be potential candidate for safe and effective controlled drug delivery over an extended period of time.

\section{Conflict of interest: None}

\section{REFERENCES}

1. Madhavi BR, Murthy VS, Rani AP, Kumar GD. Buccal film drug delivery system-an innovative and emerging technology. J Mol Pharm Org Process Res. 2013;1(3):2-6. [Full Text | DOI]

2. Ammar HO, Ghorab MM, Mohmoud AA, Shahin HL. Design and in vitro/in vivo evaluation of ultra- thin mucoadhesive buccal film containing fluticasone propionate. AAPS Pharm Sci Tech 2016;18(1):93103. [PubMed | Full Text | DOI]

3. Colley HE, Said Z, Santocildes-Romero ME, Baker SR, D’Apice K, Hansen J, et al. Pre-clinical evaluation of novel mucoadhesive bilayer patches for local delivery of clobetasol-17-propionate to the oral mucosa. Biomaterials 2018;178:134-46. [FullText | DOI]

4. Edwards PC, Kelsch R. Oral lichen planus: Clinical presentation and management. J Can Dent Assoc. 2002;68(8):494-9. [Full Text]

5. Lavanya N, Jayanthi P, Rao UK, Ranganathan K. Oral lichen planus: An update on pathogenesis and 
1. treatment. J Oral Maxillofac Pathol. 2011;15(2):127-32. [PubMed | Full Text | DOI]

2. Chaudhary H, Gauri S, Rathee P, Kumar V. Development and optimisation of fast dissolving oro-dispersible films of granisetron $\mathrm{HCl}$ using box-behnken statistical design. Bull Faculty Pharm Cairo Univ. 2013;51(2):193-201. [Full Text | DOI]

3. Jasvanth E, Teja D, Mounika B, Nalluri BN. Formulation and evaluation of ramipril mouth dissolving films. Int J Appl Pharmaceut. 2019:124-9. [Full Text | DOI]

4. Choudhary A, Tiwari G, Pandey M, Kymonil KM, Saraf SA. Formulation and characterisation of carvedilol buccal mucoadhesive patches. Int J Res Pharm Sci. 2010;1(4):396-401. [Full Text]

5. Singhal P, Jadoun GS, Sinha M, Saraf SA. Formulation and evaluation of buccal patches of terbutaline sulphate. Int J Res Pharm Sci. 2010; 1(4):440-9. [ Full Text ]

6. Choudhury A, Das S, Dhangar S, Kapasiya S, Kanango A. Development and characterisation buccoadhesive film of ciprofloxacin hydrochloride. Int J Pharm Tech Res. 2010;2(2):1050-7. [Full Text]

7. Higuchi T. Rate release of medicaments from ointment bases containing drugs in suspension. J Pharm Sci. 1961;50(10):874-5. [Full Text | DOI] 